\title{
Patient Experience during Hospital Stay: A Pilot Survey
}

\author{
Satyanarayana V. Sagi, Cong Chen, Kyaw Z. Htun, Kalyani Puvanendrampillai, \\ Medhavi Ratnayake, Joseph Ngwira, Jeyanthy Rajkanna, Samson 0. Oyibo*
}

Department of General Medicine, Peterborough City Hospital, Peterborough, UK

Email: *samoyibo@yahoo.co.uk

How to cite this paper: Sagi, S.V., Chen, C., Htun, K.Z., Puvanendrampillai, K., Ratnayake, M., Ngwira, J., Rajkanna, J. and Oyibo, S.O. (2016) Patient Experience during Hospital Stay: A Pilot Survey. Health, 8, 1518-1528.

http://dx.doi.org/10.4236/health.2016.814150

Received: October 24, 2016

Accepted: November 13, 2016

Published: November 16, 2016

Copyright $\odot 2016$ by authors and Scientific Research Publishing Inc. This work is licensed under the Creative Commons Attribution International License (CC BY 4.0).

http://creativecommons.org/licenses/by/4.0/ (c) (i) Open Access

\begin{abstract}
Introduction: Hospital inpatient care is provided to individuals who have a condition that requires them to stay in hospital. Patient experience is an important aspect of high-quality patient-centered care. Aim: With this pilot survey we aimed to obtain patient feedback on their experiences during their hospital stay, highlight areas of best practice and areas for improvement and provide a basis for a hospital-wide inpatient experience survey. Patients and Methods: Anonymous patient experience questionnaires were given to patients who were discharged from hospital during the month of May 2016. Patients were asked to answer 45 questions concerning their experience during hospital stay using the five-point Likert scale, and hand back the questionnaire before leaving the hospital. A suggestion box was provided for comments and suggestions for improvement. Results: Fifty-six questionnaires were handed out and 50 (from 27 males, 17 females and 6 patients who did not specify their gender) questionnaires were returned (89\% response rate). Most of the responses fell within the "agree" to "strongly agree" range indicating a positive patient experience for most of the items addressed. Patients also provided useful comments and suggestions. Conclusion: Results of this survey indicate that patients generally had a positive experience during their hospital stay. This survey has revealed areas for improvement, and highlights the importance of patient experience when assessing a patient-centered service.
\end{abstract}

\section{Keywords}

Patient Experience, Inpatients, Hospital Stay, Patient-Centered Care

\section{Introduction}

\section{Inpatient care}

Hospital inpatient care is provided for all individuals who have a condition that re- 
quires them to stay in hospital over one night or more. An admission to hospital could be as an emergency or as a planned admission. Health care statistics indicate that there were 15.9 million admissions to NHS hospitals in England in 2014/2015 and that this has increased compared to previous years [1]. A stay in hospital overnight can be a daunting experience for a patient and their relatives, especially if accompanied by a negative experience. Patients deserve a positive/good experience during inpatient care from the point of admission to the hospital to the point of discharge and a smooth transition to post-discharge or outpatient care.

\section{Importance of patient experience}

Patient experience is an important aspect of high-quality care and healthcare providers must understand how their inpatients are experiencing care if we are to effectively translate patient needs and preferences into higher quality, safer and more efficient inpatient services [2]. Patient satisfaction is another indicator of quality of care during hospital stay and is sometimes used synonymously with patient experience. Previous studies have highlighted important differences and discrepancies between patient experience and patient satisfaction [3]. There have been several debates concerning methodological issues around measurement and interpretation of patient experience, but when care coordination and patient engagement are at the centre of improving patient experience and outcomes, valuable information can be obtained from these surveys to facilitate quality improvement [4]. The results from patient experience measurements offer us the chance to improve care, meet patients' expectations and monitor healthcare performance through the eyes of the patient [5] [6].

\section{Aim}

The aims of this pilot survey were to obtain patient feedback on their experiences during their hospital stay, to highlight areas of best practice and areas for improvement and provide a basis for a hospital-wide inpatient experience survey.

\section{Patients and Methods}

\section{Inpatient care pathway}

Patients are admitted through the emergency department or directly to the medical assessment unit. If after initial management they require further medical investigations and treatment they are transferred to the medical ward for continuation of care before discharge. Therefore, patient care can be divided into several sections depending on their care pathway; however this survey concentrates on patient experience during care on the medical ward, which is just before discharge from hospital for most patients.

\section{Sample population}

The sample population consisted of patients who had received care on our medical ward and were being discharged during the month of May 2016. Day-case patients (patients who arrived and left the hospital the same day), patients who were incapable of 
filling in the questionnaire due to impaired cognitive function and patients who refused to participate were excluded from the survey.

\section{Questionnaires and administration}

The Patient Experience Questionnaire (PEQ) was adopted from that used for the Scottish inpatient patient experience postal survey [7]. The questionnaire consisted of 45 questions that we fashioned around five domains applicable to patient experience of care on our medical ward. The five domains used to assess patient experience were: ward facilities, medical doctors, other members of the multidisciplinary team, communication with relatives and discharge planning. Each question required one of five answers using the 5-point Likert scale (strongly agree, agree, neither agree or disagree, disagree, strongly disagree) and additional tick boxes for "does not apply" and "don't know" if necessary. There was also a section for comments/suggestions.

The PEQs were given to patients on the morning of their planned discharge. The PEQ had no patient identifiable details, were completely anonymized and were given to patients by the ward clerks as independent helpers. The time frame for the collection of the returned questionnaires was by the time the patient left the medical ward.

This patient experience survey was registered with our Quality, Governance and Compliance Department as a quality improvement project and therefore, ethical approval was not required before commencement.

\section{Data analysis}

The data obtained from this survey was analyzed both qualitatively and quantitatively. To be able to compare responses to various questions through graphical representation, the response-options on the 5-point Likert scale above were given weighting scores $(1.0,0.75,0.5,0.25$, and 0 , respectively). For each question the number of respondents who selected a response-option was multiplied by the weighting score assigned to that response-option. The sum total for all response-options produced a summative Likert score for that question. The summative Likert score was then divided by the total number of respondents to that question to produce an Agreement Score (weighted average ranging from " 1 " meaning that respondents strongly agree to that question down to " 0 " meaning that the respondents strongly disagree to that question) [8] [9] [10]. The scoring system was reversed for negative questions.

\section{Results}

\section{Sample description}

During the month of May 2016 our medical ward had a total of 80 discharges but 56 inpatients were given a copy of the questionnaire (PEQ) to be completed before leaving the hospital. Of the 24 patients that were excluded, 4 were day cases, 6 patients were not interested and the other 14 patients had impaired cognitive function and would not have been able to complete the questionnaire. Fifty patients completed the PEQ and handed them in before leaving the hospital ( $89 \%$ response rate). The group consisted of 
27 males, 17 females (and 6 patients who did not specify their gender). The group had an average age of 73 years (range: 25 -96).

\section{Response to questions}

Fifty PEQs were analyzed. Table 1 shows the questions relating to patient experience with ward facilities such as rooms, meals, noise disturbance general assistance from staff. Patients had a good (positive) experience with most of the items, however, a significant number were less happy with noise disturbance from other patients and staff, being threatened or bothered by other patients, and general assistance from staff in a reasonable time. Table 2 shows the questions relating to patient experience with the

Table 1. Questions concerning experience with ward facilities with results in whole numbers.

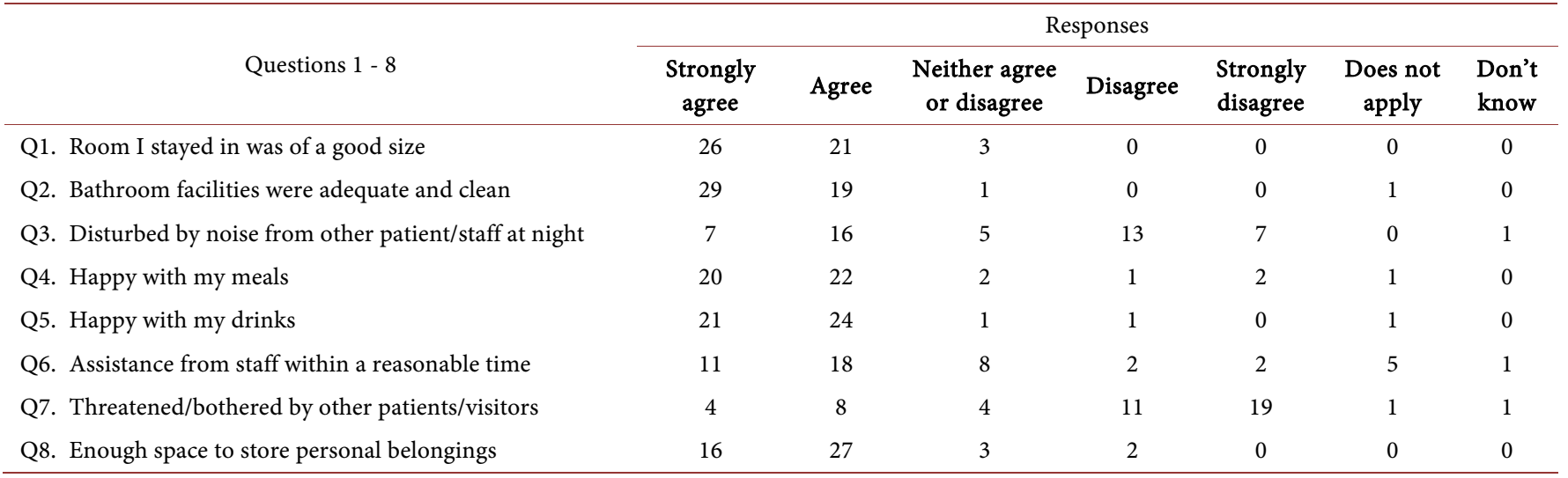

Table 2. Questions concerning experience with medical doctors with results in whole numbers.

\begin{tabular}{|c|c|c|c|c|c|c|c|}
\hline \multirow[b]{2}{*}{ Questions 1 - 11} & \multicolumn{7}{|c|}{ Responses } \\
\hline & $\begin{array}{l}\text { Strongly } \\
\text { agree }\end{array}$ & Agree & $\begin{array}{l}\text { Neither agree } \\
\text { or disagree }\end{array}$ & Disagree & $\begin{array}{l}\text { Strongly } \\
\text { disagree }\end{array}$ & $\begin{array}{l}\text { Does not } \\
\text { apply }\end{array}$ & $\begin{array}{l}\text { Don't } \\
\text { know }\end{array}$ \\
\hline Q1. Doctors knew enough about my condition and treatment & 18 & 20 & 5 & 3 & 0 & 0 & 3 \\
\hline $\begin{array}{l}\text { Q2. Doctors discussed my condition and treatment } \\
\text { in a way I could understand }\end{array}$ & 19 & 23 & 5 & 0 & 1 & 0 & 1 \\
\hline Q3. Doctors talked in front of me as if I was not there & 7 & 9 & 13 & 9 & 9 & 0 & 1 \\
\hline Q4. Doctors listened to my questions \& concerns & 13 & 23 & 7 & 3 & 0 & 1 & 0 \\
\hline Q5. Doctors washed their hands appropriately & 15 & 22 & 10 & 0 & 0 & 0 & 1 \\
\hline Q6. Confidence and trust in doctors & 20 & 21 & 5 & 1 & 0 & 0 & 0 \\
\hline $\begin{array}{l}\text { Q7. Involved as much as I wanted to be in decisions } \\
\text { about my care and treatment }\end{array}$ & 13 & 22 & 10 & 2 & 1 & 0 & 0 \\
\hline $\begin{array}{l}\text { Q8. Felt I could discuss concerns with doctor } \\
\text { and know that info would be kept confidential }\end{array}$ & 17 & 22 & 7 & 1 & 0 & 0 & 1 \\
\hline Q9. Doctors were empathetic & 13 & 27 & 6 & 1 & 0 & 0 & 2 \\
\hline Q10.Could trust the doctors looking after me & 15 & 29 & 4 & 0 & 0 & 0 & 1 \\
\hline Q11.Doctors did not cause discomfort during examination & 21 & 17 & 5 & 4 & 1 & 0 & 1 \\
\hline
\end{tabular}


medical doctors attending to them. Patients generally had a positive experience with most of the items but a significant number of patients were less happy with the fact that some doctors talked about them, in front of them, as if the patient was not there. Table 3 shows the questions relating to patient experience with other members of the multidisciplinary team such as general and specialist nurses, physiotherapists, occupational therapists and healthcare assistants. Patents generally had a positive experience with most of the items but several patients were less happy with the response to the "call bell" in good time. Table 4 shows questions relating to information being passed on to patients' relatives appropriately. Patients generally had a positive experience with most of the items in this domain. Table 5 shows the questions relating to patient experience with discharge planning. Patients generally had a positive experience with most of the items but some patients felt that they were not given enough information concerning danger signs to watch out for on leaving the hospital.

Figure 1 shows a graphical representation of the agreement scores (weighted averages of the Likert scores) for each question in ascending order. This demonstrates a median (inter-quartile range) for all scores of 0.787 (0.732 - 0.811), indicating that most of the responses to the questions fell within the "agree" to "strongly agree" range. We chose the lower quartile to represent those areas in need of urgent attention and improvement, while the upper quartile represented those areas in which we were doing exceptionally well.

Table 3. Questions concerning experience with other members of the multidisciplinary team with results in whole numbers.

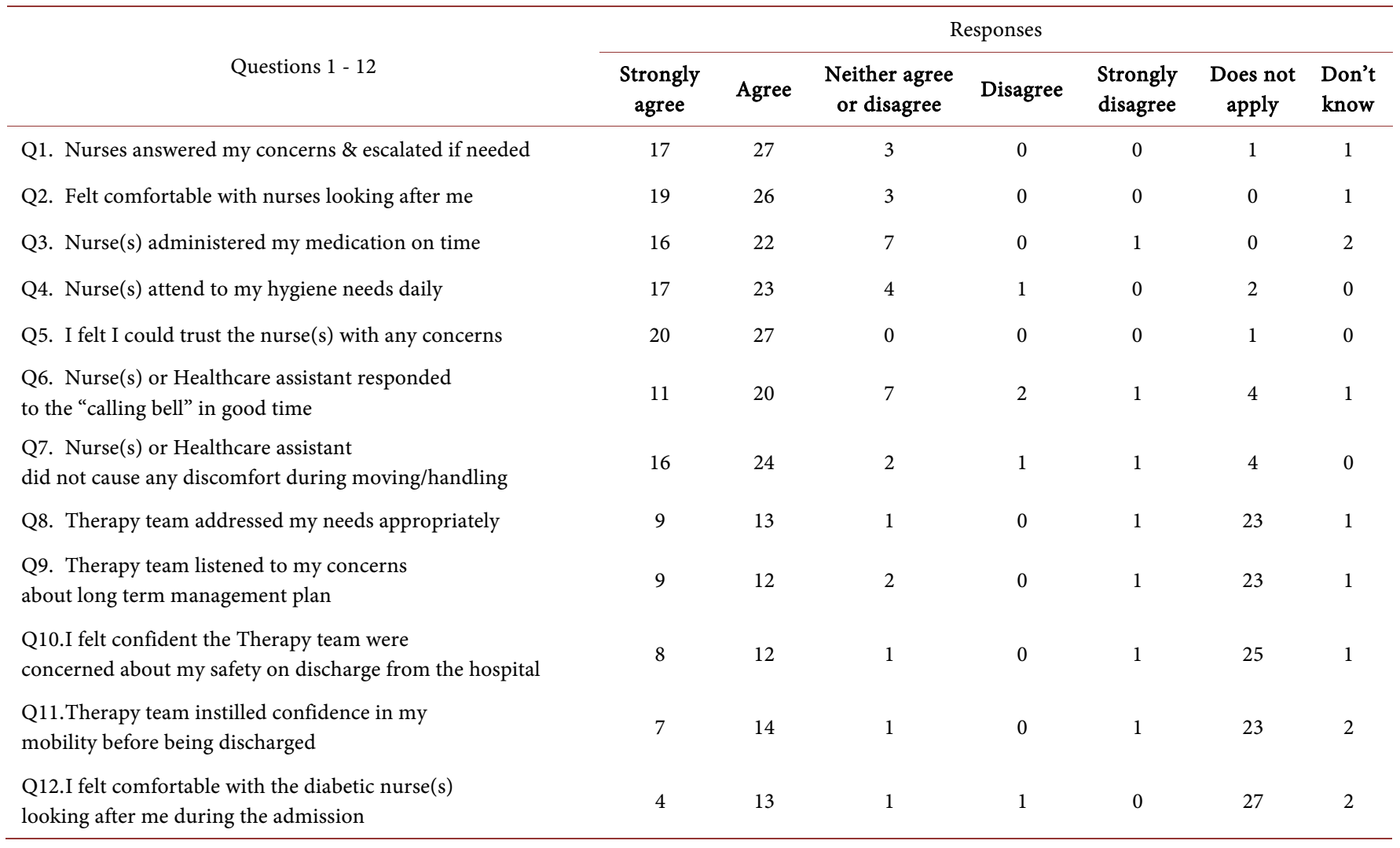


Table 4. Questions concerning experience with healthcare communication with patients' relatives with results in whole numbers.

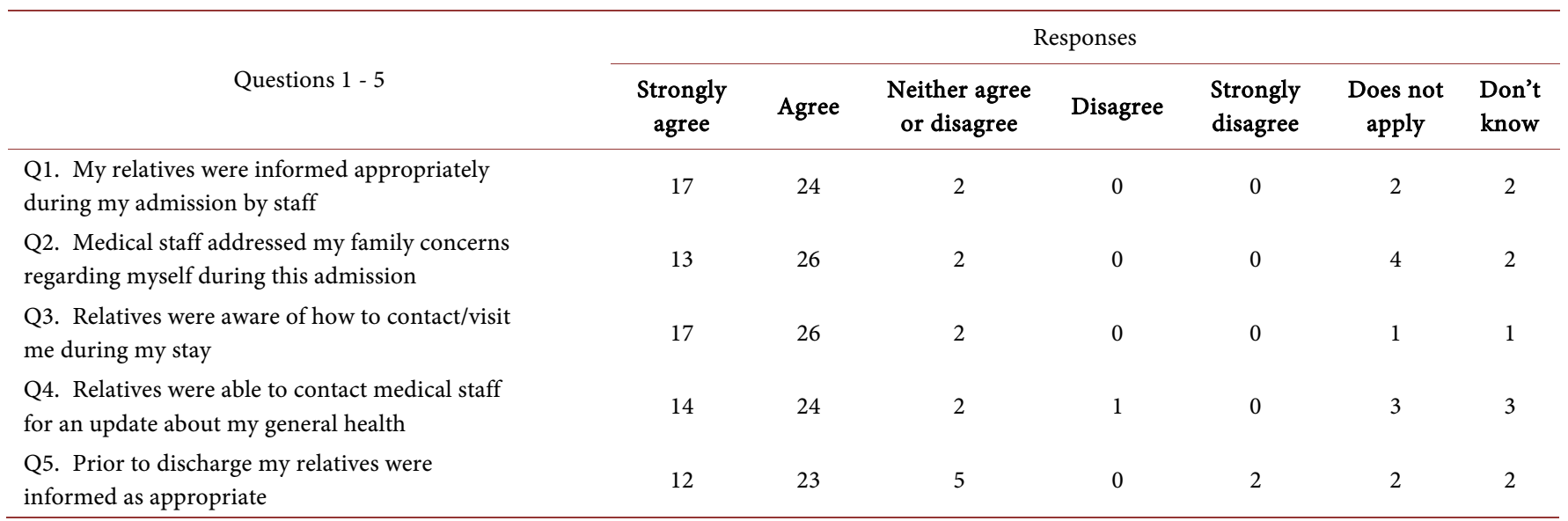

Table 5. Questions concerning experience with discharge planning with results in whole numbers.

\begin{tabular}{|c|c|c|c|c|c|c|c|}
\hline \multirow[b]{2}{*}{ Questions 1 - 9} & \multicolumn{7}{|c|}{ Responses } \\
\hline & $\begin{array}{l}\text { Strongly } \\
\text { agree }\end{array}$ & Agree & $\begin{array}{c}\text { Neither agree } \\
\text { or disagree }\end{array}$ & Disagree & $\begin{array}{l}\text { Strongly } \\
\text { disagree }\end{array}$ & $\begin{array}{l}\text { Does not } \\
\text { apply }\end{array}$ & $\begin{array}{l}\text { Don't } \\
\text { know }\end{array}$ \\
\hline Q1. I was involved in decisions about leaving hospital & 13 & 19 & 5 & 3 & 2 & 4 & 1 \\
\hline $\begin{array}{l}\text { Q2. My family/home situation was taken into } \\
\text { account when discharge planning }\end{array}$ & 16 & 19 & 3 & 2 & 1 & 5 & 1 \\
\hline Q3. Knew who to contact if questions about discharge & 10 & 15 & 10 & 2 & 1 & 5 & 3 \\
\hline Q4. Told about any danger signs to watch for when leaving hospital & 7 & 12 & 11 & 2 & 4 & 7 & 3 \\
\hline Q5. Informed about follow up plans on discharge & 10 & 15 & 8 & 1 & 3 & 6 & 3 \\
\hline Q6. Understood medications I was going home with & 12 & 17 & 7 & 1 & 2 & 5 & 2 \\
\hline Q7. Understood how and when to take my medications & 15 & 15 & 5 & 1 & 2 & 8 & 1 \\
\hline Q8. Explanation of side effects with new medications & 11 & 11 & 9 & 1 & 3 & 7 & 3 \\
\hline Q9. Felt I was safely discharged from hospital & 11 & 17 & 6 & 0 & 1 & 6 & 4 \\
\hline
\end{tabular}

\section{Lower quartile}

The lowest quartile comprised of the first 11 questions that had a score below 0.732 highlighting that these needed urgent attention. These questions related to patient experience of self-involvement with care and discharge planning, staff assistance within reasonable time, disturbance from staff and other patients, doctors conversing as if the patient was invisible, inadequate discussion about discharge medications (side-effects, uses, etc.) and discussion around danger signs to look out for on leaving the hospital.

\section{Upper quartile}

The upper quartile (scores more than 0.811 ) comprised of the last 11 questions relating to: attendance to hygiene needs, trust and confidence in both the nurses and doctors attending to them, satisfaction with drinks, rooms, adequacy and cleanliness of bathroom facilities, relative being aware of how to contact/visit and relatives being appropriately informed of their care. 


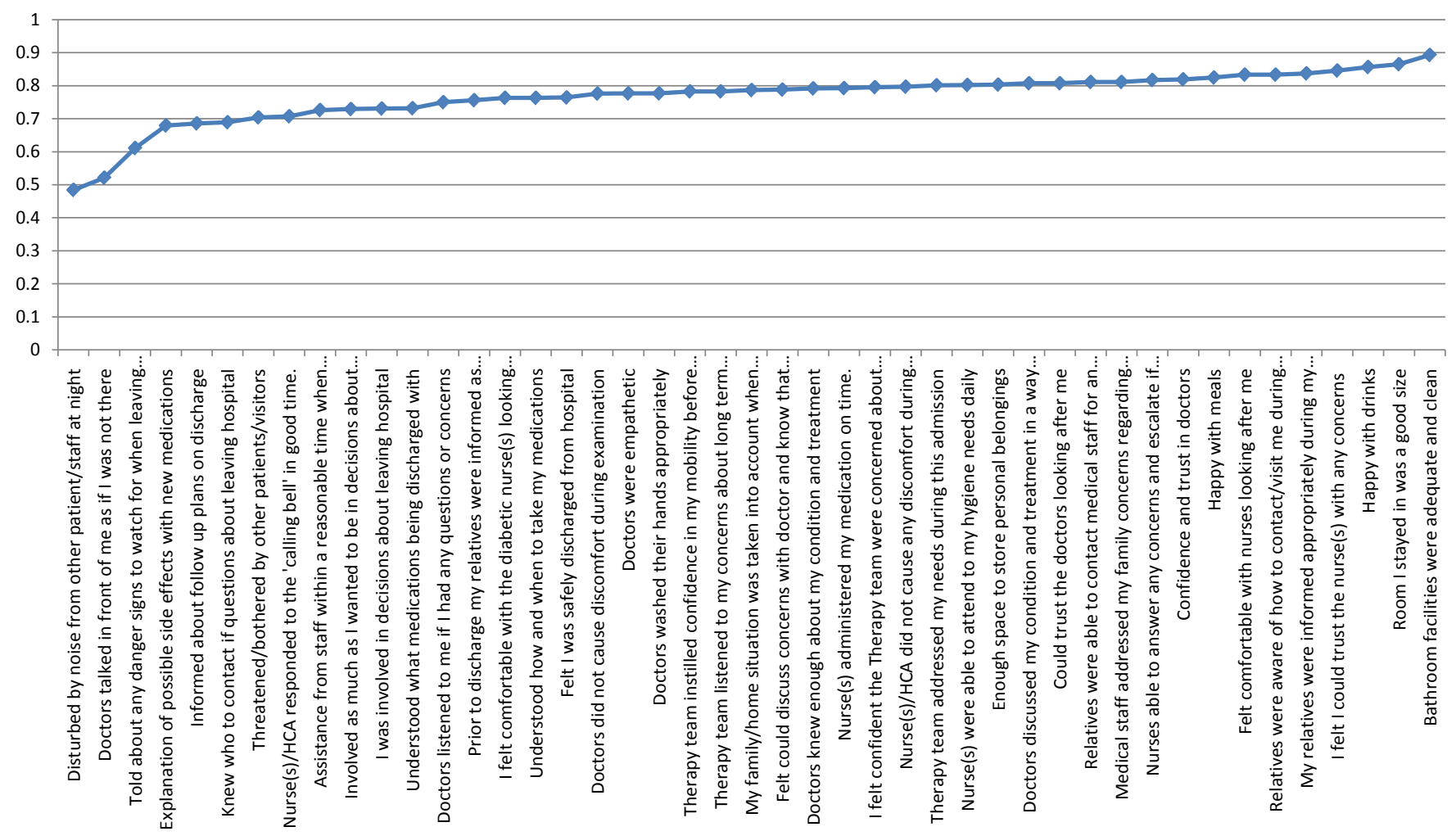

Figure 1. Graphical representation of agreement scores (weighted averages) for each question in ascending order. $\mathrm{X}$-axis $=$ list of questions; $\mathrm{Y}$-axis $=$ weighted average score on the Likert scale for each question $(1=$ strongly agree, $0.75=$ agree, $0.5=$ neither agree or disagree, $0.25=$ disagree, $0=$ strongly disagree). The first two questions had the weighting system reversed so that low scores meant poor experience with noise from other patients/staff and doctors talking in front of them as if they were invisible.

\section{Qualitative responses}

Twenty-six responders made useful comments and further suggestions for improvement to improve the experience during hospital stay. Twenty-one (80\%) of these comments indicated a positive patient experience, while the other five comments indicated areas for improvement. These comments and suggestions are shown in Figure 2.

\section{Discussion}

A positive patient experience is of paramount importance when delivering a patientcentered service. We assessed patient experience during hospital stay on our medical ward using a patient experience questionnaire. Results of this survey indicate that patients generally had a positive experience during their hospital stay.

\section{Implications to our service}

The results of this survey have provided us with valuable quantitative and qualitative information, which will help us to improve our service in relation to patients needs and thereby enhance patient experience on a medical ward. Firstly, this survey demonstrated that patients felt that they were not getting staff assistance within a reasonable time. This is an ongoing issue with increasing workload and limited resources but this is 
Comments indicating a positive experience

- Care is very good

- People were friendly

- Staff brilliant and they cared

- Very friendly and caring

- Staff very pleasant

- Staff are wonderful especially nurses and healthcare assistants

- No fault with the hospital

- All staff were kind and helpful

- I received incredible attention during my time in the Intensive Care Unit

- Looked after very well

- Critical care team was amazing

- Well looked after

- The doctors are good

- In general I was treated very well. The cleanliness is very good, the politeness was also good.

- Nurses and doctors have been very good

- All very good, nice staff

- Well looked after by nurses and other staff, no problems

- Nurses and healthcare assistants were very good.

- Excellent care

- Very happy

- Fantastic care

\section{Comments indicating need for improvement}

- They are great staff here but the system lets them down. There were not enough nurses/healthcare assistants per patient. I was left begging for pain relief for more than 2 hours on more than one occasion. As for answering call bells, some were answered quickly but there were times when they weren't answered for up to half an hour.

- I was moved when I did not want to move-very awkward for patients

- Would have loved to go to a communal day room

- Diabetes not taken into account concerning meals

- Not updated concerning medical information

Figure 2. Comments and suggestions made by responders concerning their experience during hospital stay.

being addressed. Secondly, patients indicated that they were being disturbed by staff and other patients: some felt bothered or threatened by other patients. This issue is in part related to the assorted patient case mix on medical wards. Patients who have impaired cognitive function and other patients may produce more noise for various reasons. Nursing staff continue to work through the night, which can be disturbing to some patients. Some patients need to be woken up to take their regular medication. Thirdly, some patients felt they did not get enough information about the medications they were leaving the hospital with (e.g., side-effects, what the medications were for, etc.) and danger signs to watch out for. With the joint collaboration of the nurses, doctors and pharmacist we are making improvements with this issue. Fourthly, patients wanted to be more involved with their discharge planning and know who to contact concerning questions about their discharge.

\section{Positive patient experience}

Results from our surveys demonstrate that most patients generally had a positive experience during their hospital stay on our medical ward. Hospital stay for patients can range from just a few days to a few weeks. On induction hospital staff are reminded that excellent patient care and a positive experience is the goal that should be strived for all patients and at all times. Patient feedback is essential to making continued improvements. 


\section{Previous studies in this field}

There has been several national patient inpatient experience surveys employing postal questionnaires sent after the patient has left the hospital. The Scottish Inpatient Patient Experience Survey had a 48\% response rate and assessed patient experience of care from admission to the emergency department and experience of the hospital and ward environment. Patients were most positive about environmental cleanliness, visiting hours and staff hand-washing, however they were markedly less positive about meals, nocturnal noise, knowing which nurse was in charge of the ward and discharge arrangements [7]. The National Health Service Inpatient Survey had a 47\% response rate and assessed patient experience of care from admission to discharge. Results were similar to that of the Scottish survey [2]. Our survey may have revealed similar, recurring themes that have been found during previous national surveys, however we uniquely assessed patient experience specifically during care on a medical ward by use of questionnaires given to patients and returned before they left the hospital. The response rate for our survey is also higher than that for the national postal surveys.

\section{Study limitations}

This study has its limitations. Firstly, there was a response rate of $89 \%$ for those given PEQ, which is still significantly better than that reported in other mail surveys [11] [12] [13]. However, due to the exclusion criteria, 24 patients were not given the PEQ and a further 6 patients did not return the PEQ. Therefore, our sample size represents $63 \%$ of the total number of patients discharged in that month. Secondly, we did not give the PEQ to patients with impaired cognitive function (e.g. dementia, mental health problems, etc.). As these patients were not represented in this survey there is the potential for exclusion bias. This important aspect needs to be addressed in future surveys because patients with mental health problems often have physical and mental health needs that go unrecognized [2]. The experience of patients' family members could be another way of obtaining patient experience for this under-represented group of patients. Thirdly, the fact that the PEQ was hand distributed to be returned prior to leaving the hospital could be an imposition or a rush for some patients as opposed to postdischarge postal PEQs. However, the response rate was much higher than that for postal surveys and patient recollection of events may even be better. Further randomized controlled surveys are needed to compare these two methods. Fourthly, we did not collect or control for data concerning patient sociodemographic, clinical characteristics, and length of hospital stay: a larger study is required to assess the effect of these parameters on patient experience. Lastly we excluded patients that attended and left the ward the same day. A larger study is required so that we can compare the experience between patients who were on the ward for a period of time and patients who left the same day.

\section{Conclusion}

This inpatient patient experience survey has demonstrated that patients generally had a positive experience during their hospital stay. This survey has also demonstrated areas 
for improvement on the wards, which should be the aim when using patient experience surveys to assess patient-centered care. We hope to repeat this patient experience survey on more wards after one year.

\section{Acknowledgements}

The authors greatly appreciate the hard work of Tracey Reilly and Nick Foreman who both helped with handing out and collection of the questionnaires.

\section{Author Contributions}

All eight authors, Sagi SV, Chen C, Htun KZ, Puvanendrampillai K, Ratnayake M, Ngwira J, Rajkanna J and Oyibo SO made substantial contributions to conception and design, acquisition of data, analysis and interpretation of data; contributed to drafting and revising the article; gave final approval of the version to be published; and all are in agreement to be accountable for all aspects of the work in ensuring that questions related to the accuracy or integrity of any part of the work are appropriately investigated and resolved.

\section{Disclosure}

The authors report no conflicts of interest in this work.

\section{References}

[1] Health \& Social Care Information Centre (2015) Hospital Inpatient Care: Over 10,000 More Admissions a Day than 10 Years Ago.

http://www.hscic.gov.uk/article/6836/Hospital-inpatient-care-over-10000-more-admissions -a-day-than-10-years-ago

[2] Department of Health (2008) High Quality Care for All: NHS Next Stage Review Final Report. The Stationery Office. Cm 7432.

https://www.gov.uk/government/uploads/system/uploads/attachment data/file/228836/743 2.pdf

[3] Grondahl, V.A., Wilde-Larsson, B., Karlsson, I. and Hall-Lord, M.L. (2012) Patients' Experience of Care Quality and Satisfaction during Hospital Stay: A Qualitative Study. European Journal for Person Centered Healthcare, 1, 185-192. http://dx.doi.org/10.5750/ejpch.v1i1.650

[4] Manary, M.P., Boulding, W., Staelin, R. and Glickman, S.W. (2013) The Patient Experience and Health Outcomes. New England Journal of Medicine, 368, 201-203. http://dx.doi.org/10.1056/NEJMp1211775

[5] Al-Abri, R. and Al-Balushi, A. (2014) Patient Satisfaction Survey as a Tool towards Quality Improvement. Oman Medical Journal, 29, 3-7. http://dx.doi.org/10.5001/omj.2014.02

[6] Bjertnaes, O.A., Sjetne, I.S. and Iversen, H.H. (2012) Overall Patient Satisfaction with Hospitals: Effects of Patient-Reported Experiences and Fulfillment of Expectations. BMJ Quality and Safety, 21, 39-46. http://dx.doi.org/10.1136/bmjqs-2011-000137

[7] Scottish Government (2014) Scottish Inpatient Patient Experience Survey 2014 Volume 1: National Results. http://www.gov.scot/Publications/2014/08/4194

[8] Sullivan, G.M. and Artino, A.R. (2013) Analyzing and Interpreting Data from Likert-Type 
Scales. The Journal of Graduate Medical Education, 5, 541-542.

http://dx.doi.org/10.4300/JGME-5-4-18

[9] Taylor-Powell, E. (1989) Program Development and Evaluation, Analyzing Quantitative Data. http://learningstore.uwex.edu/assets/pdfs/G3658-6.pdf

[10] Bogale, A.L., Kassa, H.B. and Ali, J.H. (2015) Patients' Perception and Satisfaction on Quality of Laboratory Malaria Diagnostic Service in Amhara Regional State, North West Ethiopia. Malaria Journal, 14, 241. http://dx.doi.org/10.1186/s12936-015-0756-6

[11] Asch, D.A., Jedrziewski, M.K. and Christakis, N.A. (1997) Response Rates to Mail Surveys Published in Medical Journals. Journal of Clinical Epidemiology, 50, 1129-1136. http://dx.doi.org/10.1016/S0895-4356(97)00126-1

[12] Bashari, W.A., Coates, R.L., Nazir, S., Riddel, N.E., Lawanson, O.O., Mohamed, A.M, and Oyibo, S.O. (2015) Patient Satisfaction with Radioiodine Treatment and Telephone Follow-Up for the Management of Thyrotoxicosis. Patient Prefer Adherence, 9, 659-664.

[13] Cummings, S.M., Savitz, L.A. and Konrad, T.R. (2001) Reported Response Rates to Mailed Physician Questionnaires. Health Services Research, 35, 1347-1355.

Submit or recommend next manuscript to SCIRP and we will provide best service for you:

Accepting pre-submission inquiries through Email, Facebook, LinkedIn, Twitter, etc.

A wide selection of journals (inclusive of 9 subjects, more than 200 journals)

Providing 24-hour high-quality service

User-friendly online submission system

Fair and swift peer-review system

Efficient typesetting and proofreading procedure

Display of the result of downloads and visits, as well as the number of cited articles

Maximum dissemination of your research work

Submit your manuscript at: http://papersubmission.scirp.org/

Or contact health@scirp.org 